\title{
Can Periodontitis Influence the Progression of Abdominal Aortic Aneurysm? A Systematic Review
}

\author{
Leila Salhi, DDS, MS' ${ }^{\oplus}$, Eric Rompen, DDS, MS, $\mathrm{PhD}^{\prime}$, Natzi Sakalihasan, MD, $\mathrm{PhD}^{2}$, \\ Isabelle Laleman, DDS ${ }^{3}$, Wim Teughels, DDS, MS, $\mathrm{PhD}^{4}$, \\ Jean-Baptiste Michel, MD, PhD, DRE ${ }^{5}$, and France Lambert, DDS, MS, PhD ${ }^{6}$
}

\begin{abstract}
There is some evidence that periodontitis increases the risk of atherothrombosis. Abdominal aortic aneurysm (AAA) is a cardiovascular disease with specific risk factors and physiopathological mechanisms that can lead to rupture in the absence of treatment. The aim of the present systematic review was to explore the influence of periodontitis on the progression of AAAs as a specific disease. A systematic search in PubMed/MEDLINE and Embase databases was performed. Human and animal studies exploring the influence of periodontal pathogens on the progression of AAA were considered for inclusion. After systematic screening, 5 articles were included in the review. Due to the heterogeneity of the selected studies, a metaanalysis could not be performed. The descriptive analyses of the studies emphasized that periodontal pathogens or their by-products contribute to systemic and local innate immunity likely to be associated with AAA physiopathology. Periodontitis seems to play a role in the development and progression of AAA. The present systematic review suggests that the presence of periodontal bacteria in the bloodstream or in situ in the vascular lesion is a risk associated with aneurysmal disease progression.
\end{abstract}

\section{Keywords}

periodontitis, periodontal pathogen, dental plaque, abdominal aortic aneurysm, Porphyromonas gingivalis

\section{Introduction}

Abdominal aortic aneurysms (AAAs) are responsible for $1 \%$ to $3 \%$ of all deaths in Western countries among men aged 65 years and older. ${ }^{1,2}$ The disease has genetic and environmental risk factors such as smoking, older age, and male gender. ${ }^{3-5}$ The estimated prevalence of AAA is between $1.3 \%$ and $12.5 \%$ in men and $1.0 \%$ and $2.2 \%$ in women. Abdominal aortic aneurysm is a chronic degenerative disorder commonly associated with an intraluminal thrombus (ILT) ${ }^{6}$ and with innate and adaptive immunities. ${ }^{7}$ The innate immunity is mainly represented by the predominant presence of neutrophils in the $\operatorname{ILT}^{8}$ and macrophages in the adventitia, and the adaptive one by the presence of lymphoid tertiary organs in the adventitia. ${ }^{7}$ The causes of the extracellular matrix (ECM) wall degradation are enzymes mainly released by the ILT components (neutrophil elastase, matrix metallopeptidase 9 [MMP-9], and plasmin). ${ }^{9}$

On the other hand, periodontitis, a chronic bacterial aggression and inflammatory response of the periodontium, ${ }^{10-12}$ affects $50 \%$ of the adult population. ${ }^{13,14}$ This chronic multifactorial disease is characterized by the invasion of gram-negative bacteria and their by-products in the periodontal tissues, leading to the destruction of the tooth support and subsequently to tooth loss. ${ }^{15-20}$ The presence of periodontal pathogens leads to the degradation of the ECM; the infiltration of neutrophils, macrophages, and lymphocytes; and the production of proteases (MMPs and serine proteases), resulting in progressive destruction of alveolar bone and finally tooth loss. ${ }^{21-27}$

\footnotetext{
'Department of Periodontology and Oral Surgery, Faculty of Medicine, University of Liège, Liège, Belgium

${ }^{2}$ Department of Cardiovascular and Thoracic Surgery, Surgical Research Centre, GIGA-Cardiovascular Science Unit, University of Liège, Liège, Belgium

${ }^{3}$ Department of Oral Health Sciences, KU Leuven \& Dentistry University Hospitals Leuven, Leuven, Belgium

${ }^{4}$ Department of Periodontology, Research Group for Microbial Adhesion, Catholic University Leuven, Leuven, Belgium

${ }^{5}$ DRE Laboratory for Translational Vascular Science, Inserm Denis Diderot University, Paris, France

${ }^{6}$ Dental Biomaterials Research Unit, Head of Clinic, Department of Periodontology and Oral Surgery, University of Liège, Liège, Belgium
}

\section{Corresponding Author:}

Leila Salhi, Department of Periodontology and Oral Surgery, Faculty of Medicine, University of Liège, CHU de Liège, Site du Sart Tilman, I Avenue de l'Hôpital, Liège 4000, Belgium.

Email: salhileila2@hotmail.com 
Similar physiopathological mechanisms are found in periodontitis as occur in AAA: ECM destruction, innate and adaptive immunity, and the role of proteolysis in the disease progression. ${ }^{28-37}$ There is consistent and strong epidemiologic evidence that periodontitis imparts increased risk of future cardiovascular disease (CVD; eg, atherosclerosis). ${ }^{38-42}$ Preclinical and clinical studies support the interaction between these 2 diseases. Tooth brushing, mastication, debridement, or scaling can induce the passage of oral pathogens, their virulent factors, or both into the bloodstream. ${ }^{43}$ It is believed that the resulting transient or prolonged bacteremia can influence cardiovascular pathogenesis. Periodontal pathogens, and more specifically Porphyromonas gingivalis ( $\mathrm{Pg})$, have been found in atherosclerotic plaques. ${ }^{44-50}$ These bacteria were also present in the muscle tissue in patients with coronary heart disease or endocarditis. ${ }^{51,45}$

Three physiopathological mechanisms were suggested for the interaction between periodontal disease and systemic diseases such as CVD. ${ }^{52}$ The first mechanism is related to the secretion of in situ pro-inflammatory markers (interleukin 1 [IL-1], IL-6, and tumor necrosis factor- $\alpha$ $[\mathrm{TNF} \alpha]$ ) caused by the presence of periodontal pathogens such as Pg, Tannerella forsythensis (Tf), Treponema denticola $(\mathrm{Td})$, Prevotella intermedia $(\mathrm{Pi})$, or their virulence factors inside the periodontal tissues. This can lead to an increased systemic inflammatory status that would potentiate CVD. ${ }^{53}$ The second process is associated with the passage of oral bacteria or their by-products into the bloodstream. The third physiopathological pathway is connected with the migration of periodontal bacteria through the bloodstream and their invasion into locus minoris resistentiae (LMR) of local endothelium loss and platelet aggregation. ${ }^{51,54}$ For phylogenic reasons (coagulation and immunity are common pathways in invertebrates), bacteria have more affinity for intravascular thrombus than for other tissues within a higher organism. ${ }^{55,56}$ Once bacteria have colonized the thrombus, local innate immune cascade, including neutrophil extracellular traps (NETs) ${ }^{57}$ with subsequent disease progression. ${ }^{58,59}$

Although these pathways have been well documented for the development of atherothrombosis (ATH), the role of periodontal disease as an additional risk of the progression of AAA specifically remains poorly explored. ${ }^{45,60-65}$ Even though ATH and AAA have similarities in their pathogenesis, additional synergetic or independent factors such as increased hemodynamic force, hypercholesterolemia, or genetics promotes the AAA. Moreover, it has also been proposed that specific infection by Chlamydia pneumoniae plays a significant role in the AAA progression. ${ }^{6-68}$

Therefore, it is of interest to independently assess the influence of periodontitis and periodontal-specific bacteria on AAA development. The aim of the present systematic review was to investigate the current knowledge about the influence of periodontitis on AAA to answer the key question, "Does periodontal disease influence the progression of AAA?"
Table I. Algorithm for Electronic Search.

((((()((“periodontitis”) OR “periodontal pathogen”) OR “dental plaque”) OR “porphyromonas gingivalis” [MeSH Terms]) OR "aggregatibacter actinomycetemcomitans" [MeSH Terms]) OR "prevotella intermedia" [MeSH Terms]) OR "treponema denticola" [MeSH Terms]) OR "tannerella forsythia" [MeSH Terms]) AND "aortic aneurysm, abdominal” [MeSH Terms]) OR (("abdominal aortic aneurysm expansion" OR "abdominal aortic aneurysm growth" OR "abdominal aortic aneurysm progression” OR "abdominal aortic aneurysm rupture" OR "abdominal aortic aneurysm thrombosis" OR "abdominal aortic aneurysm thrombus"))

\section{Materials and Methods}

\section{Study Design}

The present study was designed as a systematic review focusing on the relationship between AAA and periodontitis. The Preferred Reporting Items for Systematic Reviews and MetaAnalyses for Network Meta-analyses checklist and guidelines for systematic review were followed. ${ }^{69}$ All studies involving AAA and periodontitis were assessed. Due to a limitation of data in humans, animal studies were also included.

\section{Focused Question and Search strategy}

The controlled vocabulary (MeSH terms) and free keywords in the search strategy were defined based on the following focus question and PECO framework (P: population, E: exposure, C: control, O: outcome $)^{70}$ : "Does periodontitis influence the progression of abdominal aortic aneurysms"? This question is addressed according to the following criteria:

- Population: Animals or humans or both presenting AAA

- Exposure: Exposed to periodontitis or periodontal pathogens

- Control: Not exposed to periodontitis or periodontal pathogens

- Outcome: AAA growth, expansion, rupture, or progression

The search algorithm is shown in Table 1. An electronic search of the literature was performed using PubMed/MEDLINE and Embase. Selected publications were collected in Reference Manager software (Endnote X7, Thomson Reuters, New York, New York) until June 2017; duplicates were discarded electronically. In addition, a manual search was carried out on the reference lists of all potentially eligible studies obtained as full text.

\section{Study Selection and Statistical Analysis}

Two independent reviewers (L.S. and D.V.) screened titles, then abstracts, and finally full texts of all articles identified by the electronic and manual searches. The level of agreement 
between the reviewers was calculated using the Cohen $\kappa$ coefficient at each level of selection.

To enhance sensitivity, records were removed only if both reviewers excluded them based on the titles. In case of disagreements, a discussion with a third reviewer (F.L.) resolved the issue. The selection was done according the inclusion and exclusion criteria (see below). No statistical meta-analysis was performed, but in studies, a $P<.05$ was considered significant.

\section{Assessment of Study Quality}

Quality assessments were performed according to the AMSTAR methodological quality assessment of systematic reviews $^{71}$ (Supplementary Appendix II). Each animal or human study was rated independently based on its quality by 2 reviewers, using the criteria outlined in the Systematic Review Centre for Laboratory Animal Experimentation Office of Health Assessment ${ }^{72}$ and Translation (risk of bias) tool. ${ }^{73}$ The tool contains 10 entries that are related to selection bias, performance bias, detection bias, attrition bias, reporting bias, and other biases (Supplementary Appendix III and IV). ${ }^{72}$

\section{Inclusion and Exclusion Criteria}

The inclusion criteria were (1) animal or human studies, (2) studies focusing on the relationship between periodontitis and AAA growth or progression or expansion or rupture or thrombosis, (3) in vivo studies, and (4) randomized controlled clinical trials, case-control studies, prospective clinical series, and retrospective studies.

The exclusion criteria were (1) literature reviews, (2) editorials, (3) studies involving AAA not related to periodontitis, (4) studies involving the relationship between periodontitis and CVDs but not specifically AAA, and (5) studies involving AAA treatment.

\section{Data Extraction}

All selected studies were read carefully to identify the following data.

For human studies:

- Author(s) and year of publication

- Study design

- Objectives of the study

- Number and origin of the AAA biopsy in the test and control groups

- Methods for periodontitis identification and characterization

- Periodontitis prevalence and type and proportion of the pathogens

- Size of the aortic diameter or size of the thrombus

- Detection of local inflammation in the vascular wall or in the thrombus

- Retrieved periodontal DNA in the vascular wall

- Conclusion of the authors
For animal studies:

- Author(s) and year of publication

- Animals species and variety

- Experimental model/aneurysm induction method

- Objectives of the study

- Type of periodontal pathogens

- Study design and groups distribution

- Size of the AAA diameter

- Plasmatic inflammatory biomarkers

- Detection of local inflammation in the vascular wall or in the thrombus

- Retrieved periodontal DNA in the vascular wall

- Conclusion of the authors

In cases of missing data, the authors were contacted by e-mail to collect the information.

\section{Results}

\section{Search and Selection}

The search strategy and selected publications are shown in Figure 1 and Tables 2 and 3. The Embase and PubMed search strategy resulted in 297 articles. After screening the titles, 289 $(97.3 \%)$ and $288(97.0 \%)$ were excluded, respectively, by the first and second reviewers, resulting in a Cohen $\kappa$ coefficient of .94 (95\% confidence interval, 0.82-1.0). Nine titles were selected for abstract reading, of which 3 were excluded $(\kappa=$ 1.0). After full-text assessments, 1 article was additionally excluded. Finally, both reviewers agreed to include 5 articles in the systematic review. The studies excluded and the reasons for exclusion are reported in Supplementary Appendix I. Five articles were found eligible for a systematic review, but a metaanalysis could not be performed due to the heterogeneity of the studies.

\section{Study Characteristics}

There was substantial heterogeneity between studies in terms of study design. One study was a human observational study, ${ }^{65}$ 1 ex vivo human study, ${ }^{62} 2$ were ex vivo animal studies, ${ }^{60,74}$ and 1 study involved ex vivo samples from both animals and humans. ${ }^{75}$ The relationship between AAA and periodontitis was explored in several ways: correlating clinical periodontal measurements with the presence of AAA, ${ }^{65}$ bacterial detection by polymerase chain reaction (PCR) in different fluids (saliva, subgingival plaque, blood) or in the aneurysm, ${ }^{62,75,64}$ immunohistochemical analyses, ${ }^{74}$ and analysis of the AAA volume. ${ }^{74,60,75}$ An attempt was made to present a qualitative report for both clinical and preclinical studies. Details are presented in Tables 2 and 3.

In a clinical study, ${ }^{66}$ investigating the incidence and the severity of periodontitis in patients with AAA versus patients with non-AAA CVD (myocardial ischemia, arrhythmia, heart failure, and valvular disease), the authors observed that patients affected by AAA presented a more severe periodontitis (deeper mean pocket depth) than those without AAA. However, they 


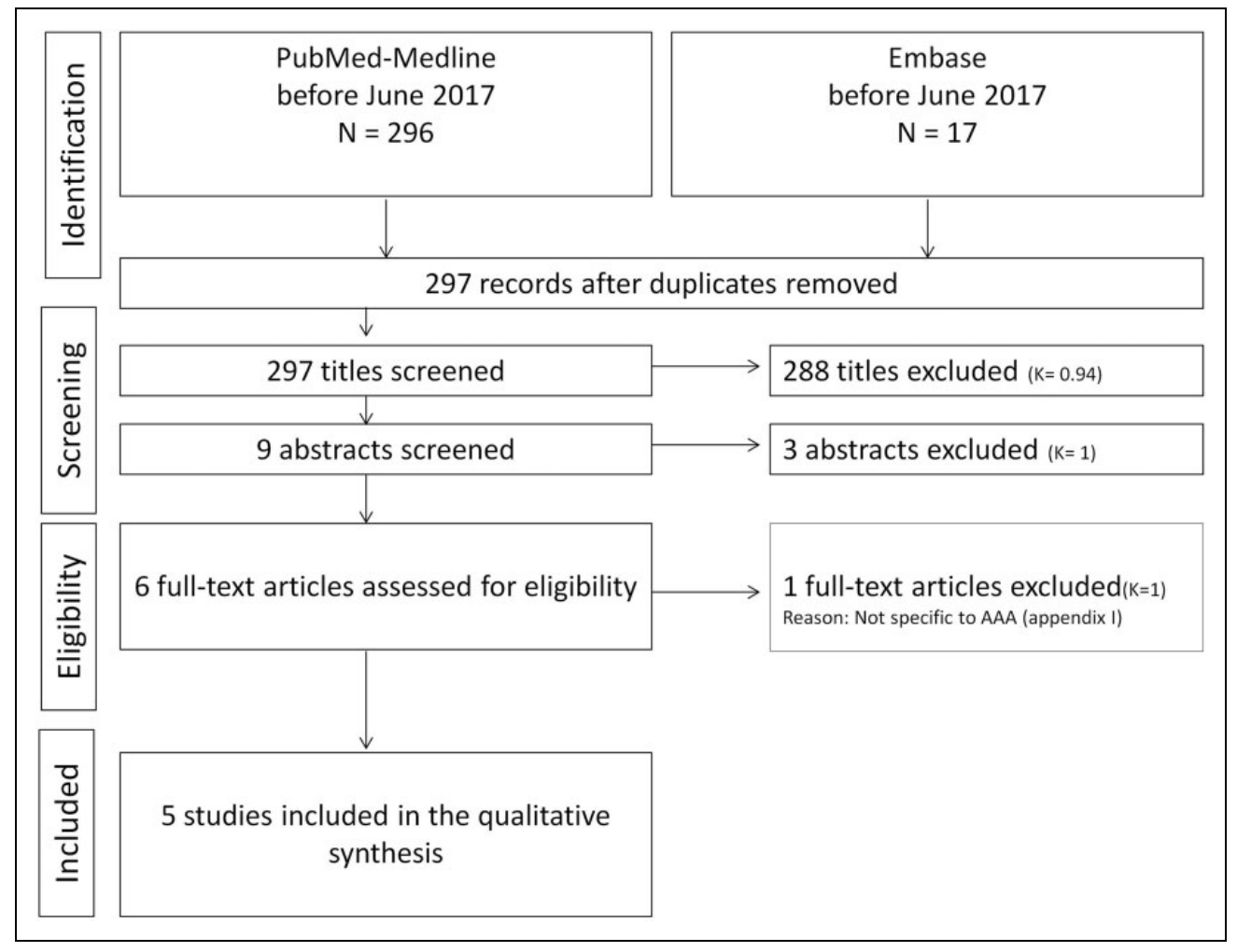

Figure I. Diagram of article selection process-Search strategy.

found similar periodontal bacteria in saliva and subgingival plaque samples for the 2 groups. The authors concluded that periodontitis may have a stronger influence on the progression of AAA than on other CVDs. In another clinical study, ${ }^{62}$ all patients with AAA presented with periodontitis. Clinical evaluations revealed that the periodontitis was moderate in $22 \%$ of patients (7/32), severe in $63 \%$ of patients (20/32), and $16 \%$ of the patients $(5 / 32)$ were edentulous. Periodontal bacteria were found in $88 \%$ of their oral samples (saliva or subgingival plaque or both), and most of the detected pathogens were Pg (81\%), followed by Tf (72\%), Td (59\%), Pi (41\%), Campylobacter rectus (34\%), Prevotella nigrescens (19\%), and Actinobacillus actinomycetemcomitans (3\%). The authors concluded that all patients with AAA had poor periodontal conditions from clinical and microbiological points of view.

In 3 preclinical studies ${ }^{60,74,75}$ in rats or mice, the intravenous (IV) or subcutaneous (SC) injection of Pg led to a significant increase in the abdominal aortic diameter or to an expansion of the ILT $(P<.03$ for mice and $P<.05$ for rat studies). In the clinical part of their study, Delbosc et a $7^{75}$ highlighted a significant correlation between $\mathrm{Pg}$ antibodies and the AAA diameter and its thrombus volume $(r=0.731, P<.0001)$. The 4 studies concluded that Pg infection was linked to the growth of the AAA.

The physiopathological pathways of how periodontitis may influence AAA pathogenesis were explored in 3 preclinical and 2 clinical studies. The possible relationship between the 2 diseases involves the presence of systemic periodontal pathogens leading to (1) an increase in plasmatic inflammatory and immunologic biomarkers, (2) a local innate and adaptive process in the AAA thrombus and wall, and (3) retrieval of periodontal bacterial DNA in AAA lesions.

Increase in plasma-free DNA and proteases and immunologic biomarkers. In 2 preclinical studies, ${ }^{74,75}$ repeated SC or IV injections of $\mathrm{Pg}$ in mice and rats induced an elevated level of nonspecific periodontal biomarkers such as MMP-2, MMP-9, and cell-free DNA (cf-DNA). In the ILT of rats that received IV Pg injections, an increase in plasma cf-DNA $(P<.0001)$ indicating the presence of the NETs was observed. ${ }^{75}$ From these results, the authors concluded that systemic neutrophil diapedesis within the ILT, ${ }^{76,77}$ a recognized risk factor for the development of AAA, can be induced by periodontal bacteria and may promote AAA progression. In addition, in a clinical study, Pg antibodies and cf-DNA were found in the plasma of patients with AAA. ${ }^{75}$ The authors noted the consistent correlation between these biomarkers and AAA diameter and thrombus volume. The 3 studies concluded that Pg induces local accumulation of neutrophils and may initiate or accelerate the growth of the AAA.

Local inflammatory process in the AAA wall or thrombus. In 3 preclinical studies in mice or rats, the inoculation of Pg induced the destruction of the abdominal aortic ECM due to local response to Pg trapping inside the ILT and AAA wall consequences, involving the fragmentation of the elastic fibers $(P<.05)$ by metalloproteases MMP-2 and MMP- $9^{60,75,78}$ and serine proteases (leukocyte elastase, u-PA, cathepsin G, 
Table 2. Results Preclinical Studies.

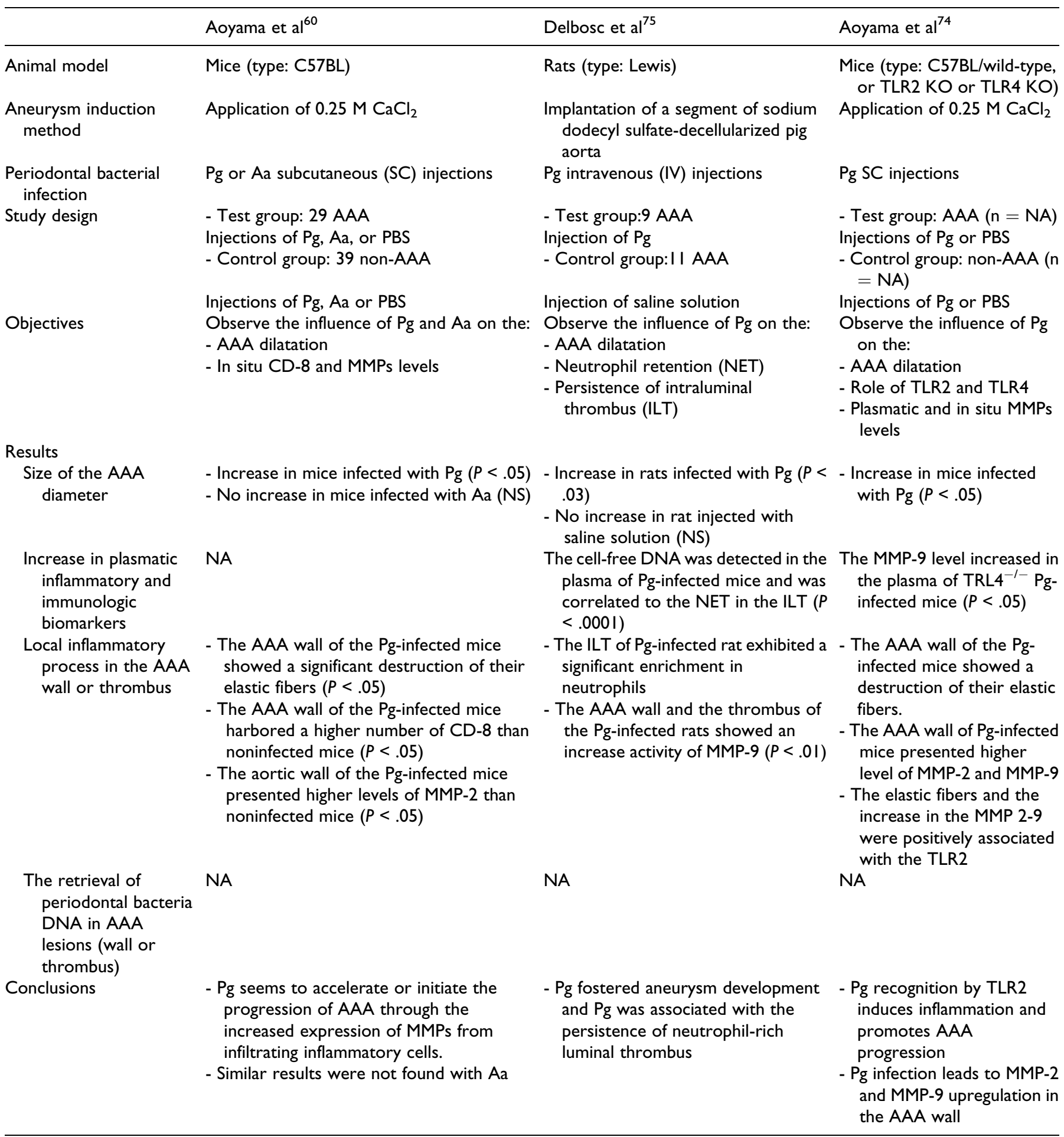

Abbreviations: Aa, Actinobacillus actinomycetemcomitans; AAA, abdominal aortic aneurysm; KO, knockout; MMP, matrix metallopeptidase; NA, not applicable; NET, neutrophil extracellular trap; PBS, phosphate-buffered saline; Pg, Prophyromonas gingivalis; TLR, Toll-like receptor.

plasmin). ${ }^{79,80}$ In 2 of these preclinical studies ${ }^{75,78}$ and 1 clinical study, ${ }^{76}$ an increased number of inflammatory cells, namely, CD-8, neutrophil (NET), and cf-DNA as well as Pg antibodies, were found in the aneurysmal wall and in the ILT. The 4 studies concluded that $\mathrm{Pg}$ seems to promote the progression of the
AAA through increasing inflammation in the wall or in the thrombus of the AAA.

Retrieval of periodontal bacteria DNA in AAA lesions. In the ex vivo analyses of human AAA, 2 authors ${ }^{62,75}$ found genetic material 


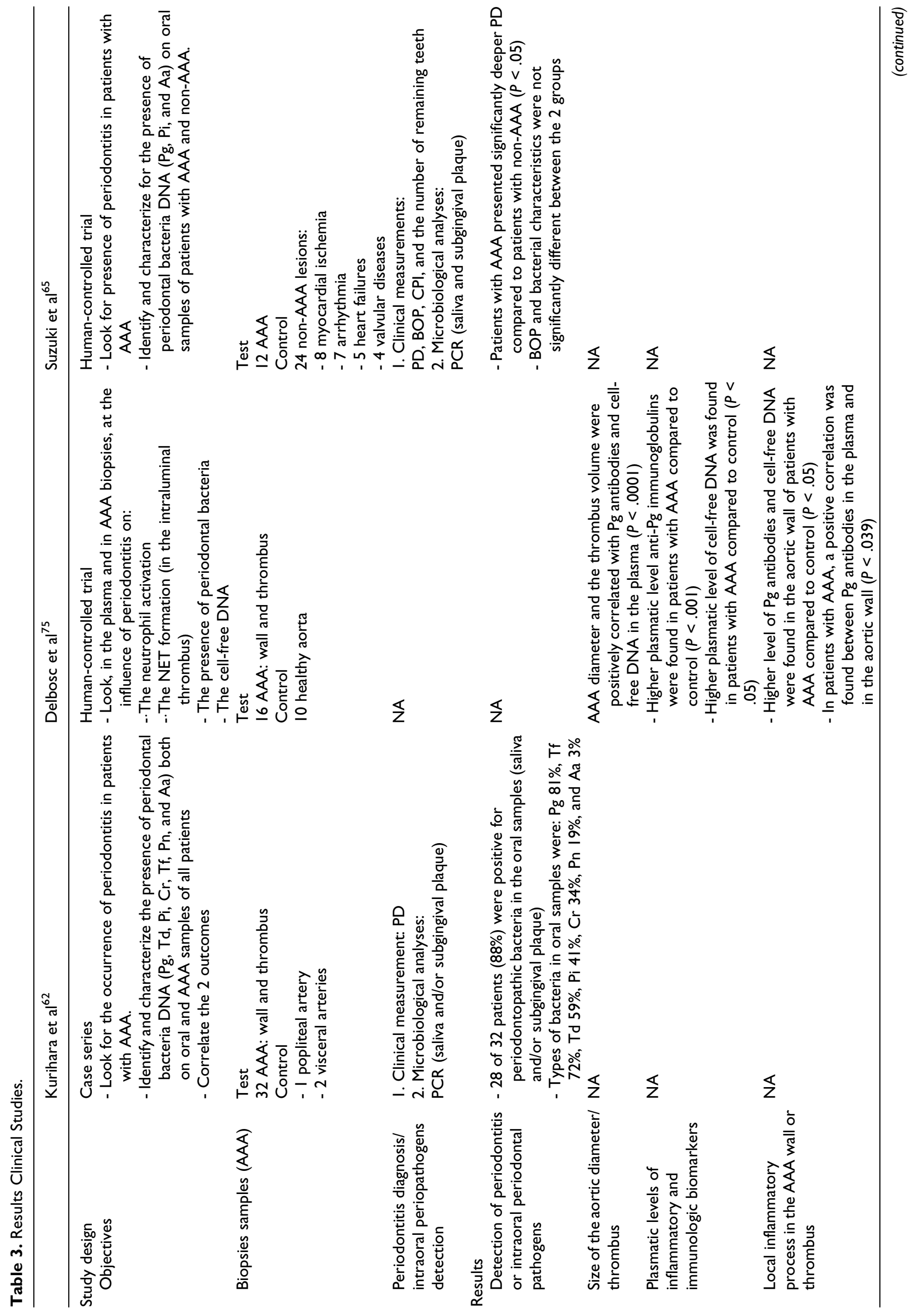




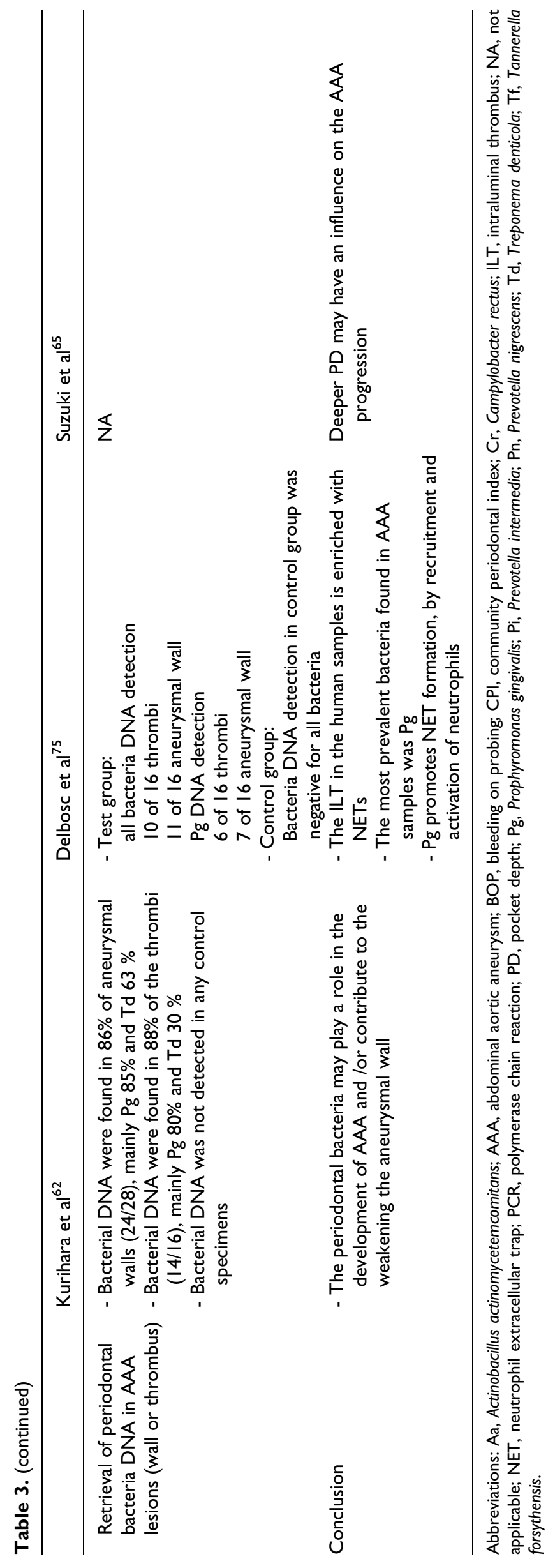


of periopathogens and antibodies specific to periodontal bacteria or Pg-lipopolysaccharide (Pg-LPS) in AAA thrombi or in the aneurysmal wall. The authors concluded that periodontal bacteria contribute directly to weakening the aneurysmal wall and that the prevention or the treatment of periodontitis may limit AAA progression.

\section{Discussion}

Periodontitis is a chronic inflammatory disease caused by dental plaque, more specifically by gram-negative anaerobic bacteria accumulation in periodontal pockets. The bacterial species forms a bacterial complex described by Socransky ${ }^{19}$; among them, the orange and the red clusters are specific for periodontitis. The red one involves $\mathrm{Td}, \mathrm{Pg}$, and $\mathrm{Tf}$, and the orange bacterial association is characterized by Fusobacterium nucleatum and Pi. Inside this complex, bacteria exchange nutrients, virulence factors and/or factors of resistance such as cytotoxins, proteases, hemagglutinin, and LPS were able to neutralize local host defenses. ${ }^{81,82}$ Therefore, the imbalance between host-parasite interactions participates in disease progression. ${ }^{83,84}$ Moreover, due to mastication and tooth brushing, these specific pathogens or their endotoxins can reach the systemic blood circulation, ${ }^{85,86}$ where they are destroyed by the reticuloendothelial system, or they colonize different intravascular sites such as the LMR. ${ }^{52,87,88}$ The consequences of these metastatic infections are an augmentation of host inflammation and influence the development of systemic diseases such as CVDs, diabetes, and preterm birth. ${ }^{89-93}$

As demonstrated, Pg participates in the CVD progression due to its fixation on the atheroma as LMR. ${ }^{47,48,50,94-96}$ These particular anaerobic, cram-negative bacteria can aggregate in red blood cells due to its capacity of hemagglutination ${ }^{97,98}$; they also affect blood cholesterol levels ${ }^{99-104}$ and therefore participate in thrombosis. Already in 2009, Paraskevas et $\mathrm{al}^{105}$ in a literature review considered the possible mechanisms involved between AAA and periodontitis, namely, the role of the inflammatory response and the effect on periodontal pathogens in the tissues of the host.

The present systematic review highlighted AAA as LMR for periodontal pathogens and how periodontal bacteria could participate in this particular CVD progression. To interpret the association between the 2 diseases, it is prudent to emphasize certain aspects of AAA pathogenesis. The disease involves a thinner arterial wall with (1) the production of circulating cytokines (IL-1, IL-6, and TNF $\alpha$ ), MMPs, and serine proteases with high proteolytic activity; (2) the destruction of the structural matrix proteins, the loosening of elastic fibers, and the depletion of smooth-muscle cells; and (3) the increased amount of neutrophil in the ILT. ${ }^{6,106-122}$

The selected articles highlighted the implication of periodontitis on the ATH progression with ILT and the aortic wall as key places. The Pg DNA was detected by PCR on human aneurysmal samples, ${ }^{75,62}$ mainly in the thrombus and in the wall of the aneurysm. This corroborates the fact that the anaerobic bacteria can be transported by blood circulation and then

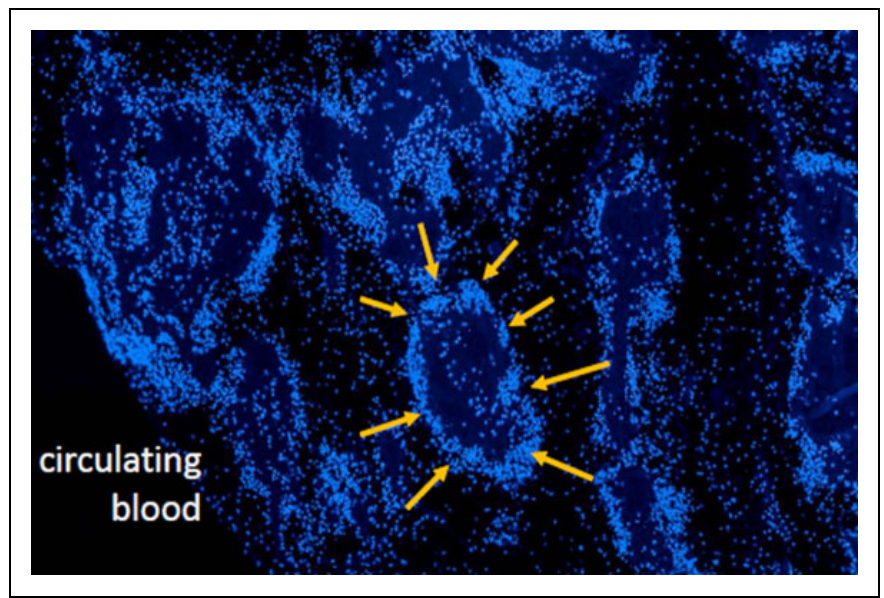

Figure 2. Locus minoris resistentiae (LMR) in intraluminal thrombus (ILT). Typical aspect of a LMR surrounded by a neutrophil crown (arrows). Within in ILT in human AAA (DAPI $\times 20)$. AAA indicates abdominal aortic aneurysm.

can reach the ILT due to its direct connection with the lumen of the vessel and also the wall of AAA. It was also suggested that Toll-like receptors (TLR-2 and TLR-4) may play a role in the AAA inflammatory process by their specific recognition of gram-negative bacteria LPS, such as Pg. ${ }^{123}$ These TLRs, found on endothelial cells, participate to increase the activation of kinases such as nuclear factor- $\kappa \mathrm{B}$ and therefore induce the cytokines activation, such as TNF $\alpha$ and IL-6, resulting in the high inflammatory activity inside the AAA wall. The mechanism of bacterial invasion on the endothelial ILT seems to involve fimbriae, specific of $\mathrm{Pg},{ }^{124,125}$ and therefore would explain the Pg DNA detection on the aneurysm samples. The consequences of Pg fimbriae anchorage would induce the expression of IL-8 and chemoattractive monocytes ${ }^{126-128}$ and therefore would participate in the increased amount of neutrophil found in the ILT as LMR (Figure 2). As demonstrated, ${ }^{75}$ Pg promotes the formation of NETs on the interface between the thrombus and the blood circulation with, as a consequence, the increase in the volume of the ILT, which stimulates the AAA growth and size. It can be assumed that the severity of periodontitis characterized by bacterial burden (quantity of periopathogens) may influence the AAA expansion. Therefore, it would be expected that patient with AAA with severe periodontitis would be more exposed to bacterial penetration in the bloodstream and more susceptible for the AAA progression compared with patients presenting mild periodontitis.

As mentioned, the disease progression also involves the destruction of elastic fibers and a high protease activity. The selected preclinical studies highlighted more elastolysis, ${ }^{60,74}$ the colonization of the abdominal aortic wall, and the ILT by inflammatory cells (CD-8, neutrophils) and a higher proteolytic activity in cases of Pg infection compared with the non-Pginfected controls. ${ }^{75}$ In these studies, the aortic wall of Pginfected animals presented higher level activity of MMP-9, suggesting more proteolytic activities and neutrophil attraction in the luminal layer of the ILT. ${ }^{116,122}$ Moreover, Pg infection 
involved a significant increase in myeloperoxidase-DNA complexes in both plasma and aneurysm samples, ${ }^{75}$ inducing oxidative stress, which participates in AAA pathogenesis, namely, by contribution to the dysregulation of MMPs and the apoptosis of smooth-muscle cells. ${ }^{117,129,130}$

Despite the limited number of available studies dealing with the relationship between AAA and periodontitis, the present systematic review suggests that the presence of periodontal bacteria in the bloodstream or in situ in the vascular lesion is a risk associated with aneurysmal disease progression.

In order to establish the relationship between these 2 chronic inflammatory diseases, further evidence is needed. Crosssectional studies correlating the AAA size with the severity of periodontitis would be of interest. Moreover, prospective multicenter study on large cohort and further exploration of surgically retrieved aneurysms should be considered.

\section{Authors' Note}

All authors substantial contributed to (1) conception and design, or acquisition of data, or analysis and interpretation of data; (2) drafting the article or revising it critically for important intellectual content; and (3) final approval of the version to be published.

\section{Declaration of Conflicting Interests}

The author(s) declared no potential conflicts of interest with respect to the research, authorship, and/or publication of this article.

\section{Funding}

The author(s) received no financial support for the research, authorship, and/or publication of this article.

\section{ORCID iD}

Leila Salhi (D) http://orcid.org/0000-0003-3529-8452

\section{Supplemental Material}

Supplemental material for this article is available online.

\section{References}

1. Sakalihasan N, Limet R, Defawe OD. Abdominal aortic aneurysm. Lancet. 2005;365:1577-89.

2. Toghill BJ, Saratzis A, Bown MJ. Abdominal aortic aneurysm an independent disease to atherosclerosis?. Cardiovasc Pathol. 2017;27:71-5.

3. Saratzis A, Dattani N, Brown A, et al. Multi-centre study on cardiovascular risk management on patients undergoing AAA surveillance. Eur J Vasc Endovasc Surg. 2017;54(1):116-22.

4. Toghill BJ, Saratzis A, Harrison SC, Verissimo AR, Mallon EB, Bown MJ. The potential role of DNA methylation in the pathogenesis of abdominal aortic aneurysm. Atherosclerosis. 2015; 241(1):121-9.

5. Saratzis A, Bown MJ. The genetic basis for aortic aneurysmal disease. Heart. 2014;100(12):916-22.

6. Michel JB, Martin-Ventura JL, Egido J, et al. Novel aspects of the pathogenesis of aneurysms of the abdominal aorta in humans. Cardiovasc Res. 2011;90(1):18-27.
7. Michel JB, Thaunat O, Houard X, Meilhac O, Caligiuri G, Nicoletti A. Topological determinants and consequences of adventitial responses to arterial wall injury. Arterioscler Thromb Vasc Biol. 2007;27(6):1259-68.

8. Michel JB, Ho-Tin-Noe B. Thrombi and neutrophils. Circ Res. 2015;116(7):1107-8.

9. Michel JB, Lattion AL, Salzmann JL, et al. Hormonal and cardiac effects of converting enzyme inhibition in rat myocardial infarction. Circ Res. 1988;62(4):641-50.

10. Allenspach-Petrzilka GE, Guggenheim B. Bacterial invasion of the periodontium: an important factor in the pathogenesis of periodontitis?. J Clin Periodontol. 1983;10(6):609-17.

11. van Palenstein Helderman WH. Microbial etiology of periodontal disease. J Clin Periodontol. 1981;8(4):261-80.

12. van Winkelhoff AJ, de Graaff J. Microbiology in the management of destructive periodontal disease. J Clin Periodontol. 1991; 18(6):406-10.

13. Eke PI, Wei L, Borgnakke WS, et al. Periodontitis prevalence in adults $>/=65$ years of age, in the USA. Periodontol 2000. 2016; 72(1):76-95.

14. Nazir MA. Prevalence of periodontal disease, its association with systemic diseases and prevention. Int J Health Sci (Qassim). 2017;11(2):72-80.

15. Dzink JL, Tanner AC, Haffajee AD, Socransky SS. Gram negative species associated with active destructive periodontal lesions. J Clin Periodontol. 1985;12(8):648-59.

16. Haffajee AD, Socransky SS, Smith C, Dibart S. Relation of baseline microbial parameters to future periodontal attachment loss. $J$ Clin Periodontol. 1991;18(10):744-50.

17. Listgarten MA, Levin S. Positive correlation between the proportions of subgingival spirochetes and motile bacteria and susceptibility of human subjects to periodontal deterioration. J Clin Periodontol. 1981;8(2):122-38.

18. Offenbacher S, Odle B, van Dyke T. The microbial morphotypes associated with periodontal health and adult periodontitis: composition and distribution. J Clin Periodontol. 1985;12(9):736-49.

19. Socransky SS, Haffajee AD, Cugini MA, Smith C, Kent RL Jr. Microbial complexes in subgingival plaque. J Clin Periodontol. 1998;25(2):134-44.

20. Socransky SS, Haffajee AD, Smith C, Dibart S. Relation of counts of microbial species to clinical status at the sampled site. J Clin Periodontol. 1991;18(10):766-75.

21. Kinane DF, Zhang P, Benakanakere M, et al. Experimental gingivitis, bacteremia and systemic biomarkers: a randomized clinical trial. J Periodontal Res. 2015;50(6):864-9.

22. Kinane DF, Cullen CF, Johnston FA, Evans CW. Neutrophil chemotactic behaviour in patients with early-onset forms of periodontitis (I). Leading front analysis in Boyden chambers. J Clin Periodontol. 1989;16(4):242-6.

23. Kinane DF, Cullen CF, Johnston FA, Evans CW. Neutrophil chemotactic behaviour in patients with early-onset forms of periodontitis (II). Assessment using the under agarose technique. J Clin Periodontol. 1989;16(4):247-51.

24. Zafiropoulos GG, Flores-de-Jacoby L, Plate VM, Eckle I, Kolb G. Polymorphonuclear neutrophil chemiluminescence in periodontal disease. J Clin Periodontol. 1991;18(8):634-9. 
25. Chang YC, Yang SF, Lai CC, Liu JY, Hsieh YS. Regulation of matrix metalloproteinase production by cytokines, pharmacological agents and periodontal pathogens in human periodontal ligament fibroblast cultures. J Periodontal Res. 2002;37(3):196-203.

26. Ejeil AL, Igondjo-Tchen S, Ghomrasseni S, Pellat B, Godeau G, Gogly B. Expression of matrix metalloproteinases (MMPs) and tissue inhibitors of metalloproteinases (TIMPs) in healthy and diseased human gingiva. J Periodontol. 2003;74(2):188-95.

27. Dong W, Xiang J, Li C, Cao Z, Huang Z. Increased expression of extracellular matrix metalloproteinase inducer is associated with matrix metalloproteinase-1 and -2 in gingival tissues from patients with periodontitis. J Periodontal Res. 2009;44(1):125-32.

28. Sorsa T, Gursoy UK, Nwhator S, et al. Analysis of matrix metalloproteinases, especially MMP-8, in gingival creviclular fluid, mouthrinse and saliva for monitoring periodontal diseases. Periodontol 2000. 2016;70(1):142-63.

29. Sorsa T, Tjaderhane L, Konttinen YT, et al. Matrix metalloproteinases: contribution to pathogenesis, diagnosis and treatment of periodontal inflammation. Ann Med. 2006;38(5):306-21.

30. Meyle J, Chapple I. Molecular aspects of the pathogenesis of periodontitis. Periodontol 2000. 2015;69(1):7-17.

31. Emingil G, Han B, Gurkan A, et al. Matrix metalloproteinase (MMP)-8 and tissue inhibitor of MMP-1 (TIMP-1) gene polymorphisms in generalized aggressive periodontitis: gingival crevicular fluid MMP-8 and TIMP-1 levels and outcome of periodontal therapy. J Periodontol. 2014;85(8):1070-80.

32. Sapna G, Gokul S, Bagri-Manjrekar K. Matrix metalloproteinases and periodontal diseases. Oral Dis. 2014;20(6):538-50.

33. Ruggiero S, Cosgarea R, Potempa J, Potempa B, Eick S, Chiquet M. Cleavage of extracellular matrix in periodontitis: gingipains differentially affect cell adhesion activities of fibronectin and tenascin-C. Biochim Biophys Acta. 2013;1832(4):517-26.

34. Letra A, Silva RM, Rylands RJ, et al. MMP3 and TIMP1 variants contribute to chronic periodontitis and may be implicated in disease progression. J Clin Periodontol. 2012;39(8):707-16.

35. Sorsa T, Tervahartiala T, Leppilahti J, et al. Collagenase-2 (MMP-8) as a point-of-care biomarker in periodontitis and cardiovascular diseases. Therapeutic response to non-antimicrobial properties of tetracyclines. Pharmacol Res. 2011;63(2):108-13.

36. Sorsa T, Mantyla P, Tervahartiala T, Pussinen PJ, Gamonal J, Hernandez M. MMP activation in diagnostics of periodontitis and systemic inflammation. J Clin Periodontol. 2011;38(9):817-9.

37. Travis J, Pike R, Imamura T, Potempa J. Porphyromonas gingivalis proteinases as virulence factors in the development of periodontitis. J Periodontal Res. 1997;32(1 Pt 2):120-5.

38. Suzuki JI, Aoyama N, Ogawa M, et al. Periodontitis and cardiovascular diseases. Expert Opin Therapeutic Targets. 2010;14(10): 1023-7.

39. Lee YL, Hu HY, Huang N, Hwang DK, Chou P, Chu D. Dental prophylaxis and periodontal treatment are protective factors to ischemic stroke. Stroke. 2013;44(4):1026-30.

40. Tonetti MS, Van Dyke TE. Periodontitis and atherosclerotic cardiovascular disease: consensus report of the Joint EFP/AAP Workshop on Periodontitis and Systemic Diseases. J Periodontol. 2013;84(suppl 4):S24-S29.
41. Tonetti MS. Periodontitis and risk for atherosclerosis: an update on intervention trials. J Clin Periodontol. 2009;36(suppl 10):15-9.

42. Bartova J, Sommerova P, Lyuya-Mi Y, et al. Periodontitis as a risk factor of atherosclerosis. J Immunol Res. 2014;2014:636893.

43. Geerts SO, Nys M, De MP, et al. Systemic release of endotoxins induced by gentle mastication: association with periodontitis severity. J Periodontol. 2002;73(1):73-8.

44. Gaetti-Jardim E Jr, Marcelino SL, Feitosa AC, Romito GA, AvilaCampos MJ. Quantitative detection of periodontopathic bacteria in atherosclerotic plaques from coronary arteries. J Med Microbiol. 2009;58(Pt 12):1568-75.

45. Wada K, Kamisaki Y. Roles of oral bacteria in cardiovascular diseases - from molecular mechanisms to clinical cases: involvement of Porphyromonas gingivalis in the development of human aortic aneurysm. J Pharmacol Sci. 2010;113(2):115-9.

46. Boillot A, Demmer RT, Mallat Z, et al. Periodontal microbiota and phospholipases: the Oral Infections and Vascular Disease Epidemiology Study (INVEST). Atherosclerosis. 2015;242(2): 418-23.

47. Mahalakshmi K, Krishnan P, Arumugam SB. Association of periodontopathic anaerobic bacterial co-occurrence to atherosclerosis - a cross-sectional study. Anaerobe. 2017;44:66-72.

48. Szulc M, Kustrzycki W, Janczak D, Michalowska D, Baczynska D, Radwan-Oczko M. Presence of periodontopathic bacteria DNA in atheromatous plaques from coronary and carotid arteries. Biomed Res Int. 2015;2015:825397.

49. Rath SK, Mukherjee M, Kaushik R, Sen S, Kumar M. Periodontal pathogens in atheromatous plaque. Indian J Pathol Microbiol. 2014;57(2):259-64.

50. Figuero E, Sanchez-Beltran M, Cuesta-Frechoso S, et al. Detection of periodontal bacteria in atheromatous plaque by nested polymerase chain reaction. J Periodontol. 2011;82(10):1469-77.

51. Zaremba M, Gorska R, Suwalski P, Kowalski J. Evaluation of the incidence of periodontitis-associated bacteria in the atherosclerotic plaque of coronary blood vessels. J Periodontol. 2007;78(2): 322-7.

52. Van Dyke TE, van Winkelhoff AJ. Infection and inflammatory mechanisms. J Periodontol. 2013;84(suppl 4):S1-S7.

53. Amar S, Gokce N, Morgan S, Loukideli M, Van Dyke TE, Vita JA. Periodontal disease is associated with brachial artery endothelial dysfunction and systemic inflammation. Arterioscler Thromb Vasc Biol. 2003;23(7):1245-9.

54. Elter JR, Hinderliter AL, Offenbacher S, et al. The effects of periodontal therapy on vascular endothelial function: a pilot trial. Am Heart J. 2006;151(1):47.

55. Engelmann B, Massberg S. Thrombosis as an intravascular effector of innate immunity. Nat Rev Immunol. 2013;13(1):34-45.

56. Massberg S, Grahl L, von Bruehl ML, et al. Reciprocal coupling of coagulation and innate immunity via neutrophil serine proteases. Nat Med. 2010;16(8):887-96.

57. Martinod K, Wagner DD. Thrombosis: tangled up in NETs. Blood. 2014;123(18):2768-76.

58. Thoden van Velzen SK, Abraham-Inpijn L, Moorer WR. Plaque and systemic disease: a reappraisal of the focal infection concept. J Clin Periodontol. 1984;11(4):209-20. 
59. Li X, Kolltveit KM, Tronstad L, Olsen I. Systemic diseases caused by oral infection. Clin Microbiol Rev. 2000;13:547-58.

60. Aoyama N, Suzuki J, Wang D, et al. Porphyromonas gingivalis promotes murine abdominal aortic aneurysms via matrix metalloproteinase-2 induction. J Periodontal Res. 2011;46(2): 176-83.

61. Alsac JM, Delbosc S, Rouer M, et al. Fucoidan interferes with Porphyromonas gingivalis-induced aneurysm enlargement by decreasing neutrophil activation. J Vasc Surg. 2013;57(3): 796-805.

62. Kurihara N, Inoue Y, Iwai T, Umeda M, Huang Y, Ishikawa I. Detection and localization of periodontopathic bacteria in abdominal aortic aneurysms. Eur J Vasc Endovasc Surg. 2004;28(5): 553-8.

63. Marques da Silva R, Caugant DA, Lingaas PS, Geiran O, Tronstad L, Olsen I. Detection of Actinobacillus actinomycetemcomitans but not bacteria of the red complex in aortic aneurysms by multiplex polymerase chain reaction. J Periodontol. 2005;76(4):590-4.

64. Nakano K, Wada K, Nomura R, et al. Characterization of aortic aneurysms in cardiovascular disease patients harboring Porphyromonas gingivalis. Oral Dis. 2011;17(4):370-8.

65. Suzuki J, Aoyama N, Aoki M, et al. High incidence of periodontitis in Japanese patients with abdominal aortic aneurysm. Int Heart J. 2014;55(3):268-70.

66. Halme S, Juvonen T, Laurila A, et al. Chlamydia pneumoniae reactive $\mathrm{T}$ lymphocytes in the walls of abdominal aortic aneurysms. Eur J Clin Invest. 1999;29(6):546-52.

67. Lindholt JS, Juul S, Vammen S, Lind I, Fasting H, Henneberg EW. Immunoglobulin A antibodies against Chlamydia pneumoniae are associated with expansion of abdominal aortic aneurysm. Br J Surg. 1999;86(5):634-8.

68. Karlsson L, Gnarpe J, Naas J, et al. Detection of viable Chlamydia pneumoniae in abdominal aortic aneurysms. Eur J Vasc Endovasc Surg. 2000;19(6):630-5.

69. Liberati A, Altman DG, Tetzlaff J, et al. The PRISMA statement for reporting systematic reviews and meta-analyses of studies that evaluate healthcare interventions: explanation and elaboration. BMJ. 2009;339:b2700.

70. Richardson WS. On questions, background and foreground. In: Wilson MC, ed. Evidence Based Healthcare Newsletter; 1997;17: 8-9.

71. Shea BJ, Grimshaw JM, Wells GA, et al. Development of AMSTAR: a measurement tool to assess the methodological quality of systematic reviews. BMC Med Res Methodol. 2007;7: 10.

72. Hooijmans CR, Rovers MM, de Vries RB, Leenaars M, RitskesHoitinga M, Langendam MW. SYRCLE's risk of bias tool for animal studies. BMC Med Res Methodol. 2014;14:43.

73. Rooney AA, Boyles AL, Wolfe MS, Bucher JR, Thayer KA. Systematic review and evidence integration for literature-based environmental health science assessments. Environ Health Perspect. 2014;122(7):711-8.

74. Aoyama N, Suzuki J, Ogawa M, et al. Toll-like receptor-2 plays a fundamental role in periodontal bacteria-accelerated abdominal aortic aneurysms. Circ J. 2013;77(6):1565-73.
75. Delbosc S, Alsac JM, Journe C, et al. Porphyromonas gingivalis participates in pathogenesis of human abdominal aortic aneurysm by neutrophil activation. Proof of concept in rats. PLoS One. 2011;6(4):e18679.

76. Fontaine V, Touat Z, Mtairag el M, et al. Role of leukocyte elastase in preventing cellular re-colonization of the mural thrombus. Am J Pathol. 2004;164(6):2077-87.

77. Houard X, Touat Z, Ollivier V, et al. Mediators of neutrophil recruitment in human abdominal aortic aneurysms. Cardiovasc Res. 2009;82(3):532-41.

78. Aoyama N, Suzuki JI, Ogawa M, et al. A periodontal pathogen accelerates the progression of abdominal aortic aneurysm via tolllike receptor-2 signaling. Circulation. 2018;124:A9403.

79. Sasajima T, Takano Y, Hiraishi Y, et al. High accumulation of plasminogen and tissue plasminogen activator at the flow surface of mural fibrin in the human arterial system. J Vasc Surg. 2000; 32(2):374-82.

80. Takagi H, Manabe H, Kawai N, Goto SN, Umemoto T. Plasma tissue plasminogen activator and abdominal aortic aneurysm presence: a systematic review and meta-analysis. Ann Vasc Surg. 2010;24(5):686-9.

81. Amano A. Host-parasite interactions in periodontitis: microbial pathogenicity and innate immunity. Periodontol 2000. 2010; 54(1):9-14.

82. Amano A. Host-parasite interactions in periodontitis: subgingival infection and host sensing. Periodontol 2000. 2010;52(1):7-11.

83. Schenkein HA. Host responses in maintaining periodontal health and determining periodontal disease. Periodontol 2000. 2006;40: 77-93.

84. Haffajee AD, Socransky SS. Microbial etiological agents of destructive periodontal diseases. Periodontol 2000. 1994;5: 78-111.

85. Forner L, Larsen T, Kilian M, Holmstrup P. Incidence of bacteremia after chewing, tooth brushing and scaling in individuals with periodontal inflammation. J Clin Periodontol. 2006;33(6):401-7.

86. Maharaj B, Coovadia Y, Vayej AC. An investigation of the frequency of bacteraemia following dental extraction, tooth brushing and chewing. Cardiovasc J Afr. 2012;23(6):340-4.

87. Craig RG, Pernat AM, Pecoits-Filho R, Levin NW, Kotanko P. Periodontal diseases and systemic inflammation. Semin Dial. 2013;26(1):23-8.

88. Van Dyke TE, van Winkelhoff AJ. Infection and inflammatory mechanisms. J Clin Periodontol. 2013;40(suppl 14):S1-S7.

89. Linden GJ, Herzberg MC. Periodontitis and systemic diseases: a record of discussions of working group 4 of the Joint EFP/AAP Workshop on Periodontitis and Systemic Diseases. J Clin Periodontol. 2013;40(suppl 14):S20-S23.

90. Papapanou PN. Systemic effects of periodontitis: lessons learned from research on atherosclerotic vascular disease and adverse pregnancy outcomes. Int Dent J. 2015;65(6):283-91.

91. Mustapha IZ, Debrey S, Oladubu M, Ugarte R. Markers of systemic bacterial exposure in periodontal disease and cardiovascular disease risk: a systematic review and meta-analysis. $J$ Periodontol. 2007;78(12):2289-302. 
92. Abariga SA, Whitcomb BW. Periodontitis and gestational diabetes mellitus: a systematic review and meta-analysis of observational studies. BMC Pregnancy Childbirth. 2016;16(1):344.

93. Wang TF, Jen IA, Chou C, Lei YP. Effects of periodontal therapy on metabolic control in patients with type 2 diabetes mellitus and periodontal disease: a meta-analysis. Medicine (Baltimore). 2014;93(28):e292.

94. Armingohar Z, Jorgensen JJ, Kristoffersen AK, Abesha-Belay $\mathrm{E}$, Olsen I. Bacteria and bacterial DNA in atherosclerotic plaque and aneurysmal wall biopsies from patients with and without periodontitis. J Oral Microbiol. 2014;6. doi: 10.3402/jom. v6.23408.

95. Tonetti MS, Van Dyke TE. Periodontitis and atherosclerotic cardiovascular disease: consensus report of the Joint EFP/AAP Workshop on Periodontitis and Systemic Diseases. J Clin Periodontol. 2013;40(suppl 14):S24-S29.

96. Figuero E, Lindahl C, Marín MJ, et al. Quantification of periodontal pathogens in vascular, blood, and subgingival samples from patients with peripheral arterial disease or abdominal aortic aneurysms. J Periodontol. 2014;85(9):1182-93.

97. Olsen I, Progulske-Fox A. Invasion of Porphyromonas gingivalis strains into vascular cells and tissue. J Oral Microbiol. 2015;7:28788.

98. Belanger M, Kozarov E, Song H, Whitlock J, Progulske-Fox A. Both the unique and repeat regions of the Porphyromonas gingivalis hemagglutin A are involved in adhesion and invasion of host cells. Anaerobe. 2012;18(1):128-34.

99. Liu F, Wang Y, Xu J, Hu R, Deng H. Effects of Porphyromonas gingivalis lipopolysaccharide on the expression of key genes involved in cholesterol metabolism in macrophages. Arch Med Sci. 2016;12(5):959-67.

100. Delbosc S, Rouer M, Alsac JM, et al. High-density lipoprotein therapy inhibits Porphyromonas gingivalis-induced abdominal aortic aneurysm progression. Thromb Haemost. 2016;115(4): 789-99.

101. Li XY, Wang C, Xiang XR, Chen FC, Yang CM, Wu J. Porphyromonas gingivalis lipopolysaccharide increases lipid accumulation by affecting CD36 and ATP-binding cassette transporter A1 in macrophages. Oncol Rep. 2013;30(3): 1329-36.

102. Jaramillo A, Lafaurie GI, Millan LV, et al. Association between periodontal disease and plasma levels of cholesterol and triglycerides. Colomb Med (Cali). 2013;44(2):80-6.

103. Maekawa T, Takahashi N, Tabeta K, et al. Chronic oral infection with Porphyromonas gingivalis accelerates atheroma formation by shifting the lipid profile. PLoS One. 2011;6(5):e20240.

104. Qi M, Miyakawa H, Kuramitsu HK. Porphyromonas gingivalis induces murine macrophage foam cell formation. Microb Pathog. 2003;35(6):259-67.

105. Paraskevas KI, Mikhailidis DP, Giannoukas AD. Periodontitis and abdominal aortic aneurysms: a random association or a pathogenetic link?. Int Angiol. 2009;28(6):431-3.

106. Crowther M, Goodall S, Jones JL, Bell PR, Thompson MM. Increased matrix metalloproteinase 2 expression in vascular smooth muscle cells cultured from abdominal aortic aneurysms. J Vasc Surg. 2000;32(3):575-83.
107. Dawson J, Cockerill G, Choke E, Loftus I, Thompson MM. Circulating cytokines in patients with abdominal aortic aneurysms. Ann N Y Acad Sci. 2006;1085:324-6.

108. Wallinder J, Bergqvist D, Henriksson AE. Proinflammatory and anti-inflammatory cytokine balance in patients with abdominal aortic aneurysm and the impact of aneurysm size. Vasc Endovasc Surg. 2009;43(3):258-61.

109. Hellenthal FA, Pulinx B, Welten RJ, et al. Circulating biomarkers and abdominal aortic aneurysm size. J Surg Res. 2012; 176(2):672-8

110. Speelman L, Hellenthal FA, Pulinx B, et al. The influence of wall stress on AAA growth and biomarkers. Eur J Vasc Endovasc Surg. 2010;39(4):410-6.

111. Hellenthal FA, Buurman WA, Wodzig WK, Schurink GW. Biomarkers of AAA progression. Part 1: extracellular matrix degeneration. Nat Rev Cardiol. 2009;6(7):464-74.

112. Petersen E, Wagberg F, Angquist KA. Proteolysis of the abdominal aortic aneurysm wall and the association with rupture. Eur J Vasc Endovasc Surg. 2002;23(2):153-7.

113. Kadoglou NP, Liapis CD. Matrix metalloproteinases: contribution to pathogenesis, diagnosis, surveillance and treatment of abdominal aortic aneurysms. Curr Med Res Opin. 2004;20(4): 419-32.

114. Palombo D, Maione M, Cifiello BI, Udini M, Maggio D, Lupo M. Matrix metalloproteinases. Their role in degenerative chronic diseases of abdominal aorta. J Cardiovasc Surg (Torino). 1999; 40(2):257-60.

115. Courtois A, Nusgens BV, Hustinx R, et al. 18F-FDG uptake assessed by PET/CT in abdominal aortic aneurysms is associated with cellular and molecular alterations prefacing wall deterioration and rupture. $J$ Nucl Med. 2013;54(10):1740-7.

116. Folkesson M, Silveira A, Eriksson P, Swedenborg J. Protease activity in the multi-layered intra-luminal thrombus of abdominal aortic aneurysms. Atherosclerosis. 2011;218(2):294-9.

117. Kim HW, Blomkalns AL, Ogbi M, et al. Role of myeloperoxidase in abdominal aortic aneurysm formation: mitigation by taurine. Am J Physiol Heart Circ Physiol. 2017;313(6): H1168-79.

118. Carrell TW, Burnand KG, Booth NA, Humphries J, Smith A. Intraluminal thrombus enhances proteolysis in abdominal aortic aneurysms. Vascular. 2006;14(1):9-16.

119. Thompson RW, Holmes DR, Mertens RA, et al. Production and localization of 92-kilodalton gelatinase in abdominal aortic aneurysms. An elastolytic metalloproteinase expressed by aneurysm-infiltrating macrophages. J Clin Invest. 1995;96(1): 318-26.

120. Keeling WB, Armstrong PA, Stone PA, Bandyk DF, Shames ML. An overview of matrix metalloproteinases in the pathogenesis and treatment of abdominal aortic aneurysms. Vasc Endovasc Surg. 2005;39(6):457-64.

121. Touat Z, Ollivier V, Dai J, et al. Renewal of mural thrombus releases plasma markers and is involved in aortic abdominal aneurysm evolution. Am J Pathol. 2006;168(3):1022-30.

122. Swedenborg J, Eriksson P. The intraluminal thrombus as a source of proteolytic activity. Ann N Y Acad Sci. 2006;1085: 133-8. 
123. Nakagomi A. Effect of Toll-like receptor in periodontal bacteriaaccelerated abdominal aortic aneurysms. Circ J. 2013;77(6):1414-5.

124. Deshpande RG, Khan MB, Genco CA. Invasion of aortic and heart endothelial cells by Porphyromonas gingivalis. Infect Immun. 1998;66(11):5337-43.

125. Deshpande RG, Khan M, Genco CA. Invasion strategies of the oral pathogen porphyromonas gingivalis: implications for cardiovascular disease. Invas Metastasis. 1998;18(2):57-69.

126. Hirose K, Isogai E, Ueda I. Porphyromonas gingivalis fimbriae induce adhesion of monocytic cell line U937 to endothelial cells. Microbiol Immunol. 2000;44(1):17-22.

127. Khlgatian M, Nassar H, Chou HH, Gibson FC 3rd, Genco CA. Fimbria-dependent activation of cell adhesion molecule expression in Porphyromonas gingivalis-infected endothelial cells. Infect Immun. 2002;70(1):257-67.
128. Nassar H, Chou HH, Khlgatian M, Gibson FC 3rd, Van Dyke $\mathrm{TE}$, Genco CA. Role for fimbriae and lysine-specific cysteine proteinase gingipain $\mathrm{K}$ in expression of interleukin-8 and monocyte chemoattractant protein in Porphyromonas gingivalis-infected endothelial cells. Infect Immun. 2002;70(1): 268-76.

129. Ramos-Mozo P, Madrigal-Matute J, Martinez-Pinna R, et al. Proteomic analysis of polymorphonuclear neutrophils identifies catalase as a novel biomarker of abdominal aortic aneurysm: potential implication of oxidative stress in abdominal aortic aneurysm progression. Arterioscler Thromb Vasc Biol. 2011; 31(12):3011-9.

130. McCormick ML, Gavrila D, Weintraub NL. Role of oxidative stress in the pathogenesis of abdominal aortic aneurysms. Arterioscler Thromb Vasc Biol. 2007;27(3):461-9. 